$11-12-2020$

\title{
Kenya: Gender effects of COVID-19-Responses from fourth round of data collection in five Nairobi informal settlements (Kibera, Huruma, Kariobangi, Dandora, and Mathare)
}

Population Council

Follow this and additional works at: https://knowledgecommons.popcouncil.org/departments_sbsr-pgy How does access to this work benefit you? Let us know!

Recommended Citation

"Kenya: Gender effects of COVID-19-Responses from fourth round of data collection in five Nairobi informal settlements (Kibera, Huruma, Kariobangi, Dandora, and Mathare)," COVID-19 Research \& Evaluations brief. Nairobi: Population Council, 2020. 


\title{
Kenya: Gender effects of COVID-19
}

\author{
Responses from fourth round of data collection in five Nairobi informal \\ settlements (Kibera, Huruma, Kariobangi, Dandora, and Mathare)
}

June 13-16, 2020

\section{Highlights}

- Women are more likely than men to report increased household tension, arguing and household violence due to COVID-19 mitigation measures, in particular those ages 25-34.

- Women are twice as likely to take on more unpaid domestic work such as cooking, cleaning and childcare compared to men due to Coronavirus. About half of both men and women reported this increase in domestic work has had a negative impact on their ability to earn money.

- While women were earning less than their male partners prior to COVID-19, this gap has been widened due to the pandemic. Half of women, compared to a third of men, report earning nothing due to coronavirus. Of those in a partnership, $44 \%$ say both they and their partner are earning less now.

- In general men have more full control over a range of decision-making areas - from leaving the house to working to household purchases. This decision making power between men and women in the household does not appear to have been changed by COVID-19.

- 4 out of 5 women do not currently want to get pregnant. About half of women were using contraception in March before COVID-19, and almost all (86\%) were still using the same method (mainly injectables and implants, therefore perhaps they have not yet needed to renew their methods during COVID-19). Of those using the same method as in March, 18\% had experienced a challenge accessing their method. Women who started a new method since Coronavirus said it was because now is not the time to get pregnant. The main reason given for not using any method is not being sexually active (73\%).

\section{Household Dynamics}

On June 13-16, a fourth round of the survey was completed via phone interviews with 1,529 adults; this represents $76 \%$ of the original COVID-19 KAP study cohort. The average age was 36 years, and $62 \%$ were female.

- $\quad 69 \%$ of the participants had a partner, of which $76 \%$ of both men and women reported they were currently living with their partner.

Of those married but not living with their partner, $68 \%$ had not seen them for at least

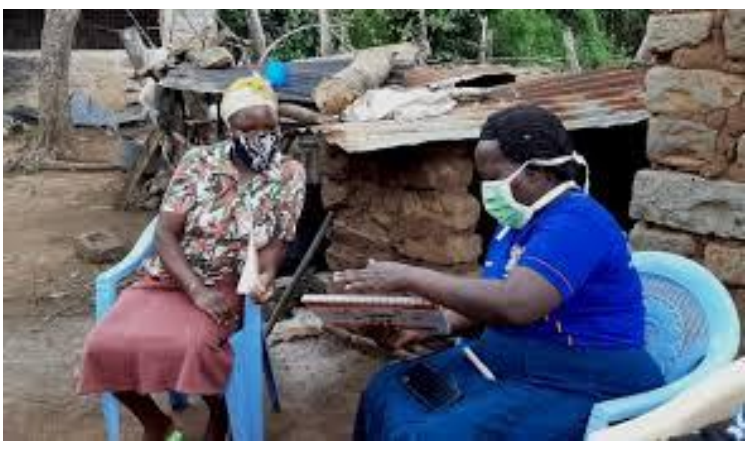
a month; this was reported more by women than men ( $75 \%$ vs $62 \%$ ).

There was no clear pattern by gender on the change in income earning balance between partners. For example, those reporting that both partners were earning less, $60 \%$ were women and $40 \%$ were men. $78 \%$ of women reported not knowing their partner's income compared to $22 \%$ of men. 
- Over the last 2 weeks, almost half (46\%) of participants said there were days they had little interest or pleasure in doing things they normally do. 1 out of 10 felt this way every day. $45 \%$ said there were days they had felt down, depressed or hopeless. 1 out of 7 felt this way every day.

- Women were slightly more likely to report feeling down or depressed (47\% vs $41 \%$ of men) and to say this was more so than before COVID-19 ( $63 \%$ of women vs $57 \%$ of men).

\section{Partner violence}

- Over the last 3 months, both women and men report increased household tension (64\%), arguing (39\%), and fear partner would harm them (10\%), in particular for women aged $25-34$. This is steadily increasing as the pandemic continues and economic strain grows with 13\%, 15\% and 5\% increases respectively each month.

- Of participants with partners, $8 \%$ of women said their male partner had physically hurt them or forced them to have sex, with $52 \%$ saying this was more than pre-pandemic.

\section{Domestic work}

- Women report taking on more domestic chores due to COVID-19, including more time spent cooking ( $51 \%$ of women vs $23 \%$ of men), cleaning (59\% of women vs $25 \%$ of men), and childcare (63\% vs $29 \%)$.

- Almost half of both men and women said this impacted their ability to earn money

\section{Income Inequalities}

- Prior to COVID-19, $16 \%$ of women and $5 \%$ of men did not earn any money and women were more likely to earn money on a daily basis than on a monthly basis as compared to men, suggesting more work in the informal sector.

- Due to COVID-19, almost all participants (88\%) said they were earning less. However, loss of income has been more severe for women with half $(48 \%)$ of women said they were earning none now compared to $33 \%$ of men.

- Reduced income affects both partners, with $84 \%$ of male participants saying their partners were earning less now, and $72 \%$ of women saying their partners were earning less now.

- Financial reliance within partnerships has changed rapidly in the past three months with over three-quarters of women, compared to half of men, experiencing a change in reliance on their partner.

- For female participants over a third said their reliance increased, while the same proportion said it had decreased

- For men, about a quarter reported an increase in reliance on their partner, while the same amount said it had decreased

\section{Decision-making}

While women had less decision-making power as compared to men across a range of situations (leaving the house, working outside the house, making purchases, etc.), change in decision making power during the COVID-19 pandemic appears to be affecting women and men equally. For example, $46 \%$ of men and $37 \%$ of women say they have full control over making the decision to visit friends or family; about half of both men (50\%) and women (51\%) say due to COVID-19, they have less decisionmaking power on this than before. It is possible that loss of decision-making power is not due to intrahousehold power dynamics but rather external factors related to COVID-19 that leave people feeling they are less in control of their lives.

\section{Sexual and Reproductive Health}

While there is unmet need for family planning, it appears to be a continuation of the pre-COVID-19 state. The main reason for discontinuation appears to be from changes in sexual activity more than access. However, that may change as time goes on as the most common methods prior to COVID-19 were injectables (44\%) and implants (20\%), which may have not yet needed to be renewed. 
- In June, $43 \%$ of women in June reported not purchasing sanitary pads in the past two weeks due to COVID-19. This increased from $36 \%$ in April.

- $\quad 22 \%$ of participants have forgone health services due to COVID-19 at least once in the last 3 months. Women are more likely to report forgoing health services due to COVID-19, and of women who skipped health services, $11 \%$ reported they skipped family planning services in the past three months. $44 \%$ of women said that skipping health care was cost related compared to $39 \%$ of men.

- $\quad$ Of all women, $80 \%$ were not currently pregnant and do not wish to become pregnant.

- Of those that were not currently pregnant or recently had a baby 4 in 5 would be somewhat or very unhappy if they got pregnant, yet only $51 \%$ are currently using a method of family planning.

- $\quad$ Of women who had been using an FP method prior to COVID-19, 86\% were using the same method as before and $13 \%$ were not using any method now.

- Approximately 1 in 5 (18\%) of those still using a method of family planning had experienced a challenge continuing to use this method because of COVID-19

- Of those who stopped using a method since the start of COVID-19, the most common reason reported was no longer being sexually active (73\%)

- Of women who had started using a method since COVID-19 started, $42 \%$ said it was because now is not the time to get pregnant, $18 \%$ said side effects or health concerns, $11 \%$ said their previous method was no longer available.

\section{Recommendations}

Women are disproportionately experiencing adverse effects of COVID-19 and mitigation policies. Of particular concern is the complete loss of income for most women and higher reporting of depressive symptoms. Women are more likely to have lost income, and say they rely on their partner more now; there is a risk that the social and economic stressors of the COVID-19 pandemic will push a return to more traditional gender roles (i.e. pressure on the man to be the breadwinner), further increasing stress and violence in the household and set back gains in gender equality.

Resources for GBV. As there is increasing tension, arguing and violence in the household, it is critical that GBV response resources remain active, supported and available. Public education on how to access these resources in a safe and confidential way is important.

Economic Resources. Women are experiencing greater losses of complete income. Gender responsive social protection should be considered to ensure that female headed households access money and do not suffer disproportionately and that recent gains in gender equality are not erased.

Sexual and Reproductive Health Services. Barriers keeping women from accessing health services should be addressed. In coming months, as more women (in particular those using injectables) need re-fills of family planning, there is risk that there will be an increase in unmet need for family planning. Public education reminders to women to refill their methods, as well as enabling them to do so, will be critical to prevent a rise in unintended pregnancy.

The Population Council conducts research and delivers solutions to improve lives. As COVID-19 spreads around the world, the Population Council is working to lessen the health, social, and economic impact of the outbreak. On the ground in 50 countries and 14 offices, our experts are partnering with governments to develop approaches for rapid research, data collection, monitoring, and mapping, and to test and evaluate behavioral interventions.

Suggested citation: Population Council. 2020. "Kenya: Gender effects of COVID-19. Responses from fourth round of data collection in five Nairobi informal settlements (Kibera, Huruma, Kariobangi, Dandora, and Mathare)"

(c) 2020 The Population Council, Inc.

\section{POPULATION} COUNCIL 